health workers including provision of health information provided to patients and instances of being mistreated.

These findings offer an understanding of ways in which spaces of health care can be more approachable, and trusted by Maasai. Incorporating cultural safety and ethical spaces to understand health care access can help to reduce the power imbalance possibly resulting from a history of marginalization.

\section{NAVIGATING KNOWLEDGE AS TRUTH IN SEXUAL HEALTH: A FOUCAULDIAN-INFORMED DISCOURSE ANALYSIS OF PRACTITIONERS' CONCEPTUALISATIONS OF RISK FOR SEXUALLY TRANSMITTED INFECTIONS IN GAY, BISEXUAL AND QUEER MEN}

N Pierce. Arden University, UK

10.1136/bmjopen-2021-QHRN.26

Mainstream health psychology conceptualises risk behaviours for sexually transmitted infections (STIs) in gay, bisexual and queer $\left(\mathrm{GBQ}^{*}\right)$ men using a biomedically informed framework that focuses on sexual health outcomes (e.g. STI diagnoses) to define sexual practices (e.g. condomless anal sex or multiple sexual partners) as 'safer' or 'risky'. Sexual health practitioners working within this framework navigate the authority of mainstream health discourses that present such information as 'truth' in their work with GBQ" clients. Relatedly, client's own experiences of sexual health and practice may be marginalised or obscured by the dominance of heteronormative and risk averse conceptualisations of risk for STIs. Reflecting on semi-structured interviews with five third sector sexual health practitioners, this paper uses Foucauldian informed discourse analysis to examine how practitioners conceptualise risk for STIs within the context of their professional roles. Three discourses were identified: 'GBQ" men as vulnerable', 'risk looks different for everyone' and 'where does responsibility come from?'. Participant's accounts indicated each of the discourses as permeating public and private, individual and societal lives in relation to sexual health. However, despite the continued interest of mainstream health discourses in minimising and containing the risks to sexual health allegedly posed by GBQ* men, participant's talk highlighted the inadequacy of the sexual health provision that constitutes and is constituted by such discourses. As such, the concept of risk for STIs in relation to GBQ* men is shown to be highly visible and socio-politically contentious, calling into question its legitimacy both as a form of 'truth' about sexual health, and as method of informing professional sexual health practice.

\section{7 'F*** WHAT THE DOCTORS TELL YOU': MISTRUST AND DISEMPOWERMENT IN FATHERS OF CHILDREN WITH LIFE LIMITING CONDITIONS}

${ }^{1} \mathrm{G}-\mathrm{I}$ Postavaru, ${ }^{1} \mathrm{H}$ Swaby, ${ }^{2} \mathrm{R}$ Swaby. ${ }^{1}$ Bishop Grosseteste University, UK; ${ }^{2}$ Queens Medical Centre, Nottingham University Hospitals NHS Trust, UK

\subsection{6/bmjopen-2021-QHRN.27}

Background, aim or objectives Despite a growing corpus of qualitative research exploring parental experiences of caring for a child with a life-limiting condition (LLC), studies focusing on fathers' needs are sparse. Their voice is often diluted within a predominant mother narrative, raising questions about their needs and support within the healthcare setting. This study aimed to provide a greater insight into the caregiving experiences of fathers with a child with an LLC.

Methods Meta-ethnography was used to synthesise existing qualitative studies exploring fathers' caregiving experiences. PubMed, PsycINFO, CINAHL and Science Direct search databases were used (up to April 2020) and qualitative, English studies were selected.

Results Sixty-three studies were included. A conceptual model of fathers' key experiences was developed. It encompassed the following overarching concepts: 'The paradox of support'; 'Challenges in the caring process'; 'Nobody thinks of men'; 'Impact on family life' and; 'The fall of the curtain: an irrevocably altered world'. This presentation will focus on the first and third named concepts, which highlighted many paradoxical experiences within the healthcare setting. The concepts of honesty, trust, mistrust, empathy, alienation and abandonment described fathers' experiences of health services and medical expert knowledge. Feeling side-lined and experiencing inconsistency in the healthcare system were also key themes. These informed fathers' experiences of disempowerment when interacting with health professionals, as well as examples of reassurance and support. These issues, as well as sensitive challenges around intimate personal/nursing care, and the impact on fathers' confidence in the caregiving process will be explored.

Conclusions This study highlights the trust and health communication needs of an increasing number of fathers who are involved in caring for an ill child. Practical recommendations are provided, for example in relation to healthcare policy, and ethical issues around the recognition of fathers in child safeguarding and dignity of care policies.

\section{TRUSTING WHO KNOWS BEST WHEN MANAGING LONG-TERM CONDITIONS IN DEMENTIA: FINDINGS FROM A QUALITATIVE STUDY OF STAKEHOLDER PERSPECTIVES}

${ }^{1} \mathrm{~J}$ Rees, ${ }^{1} \mathrm{~A}$ Burton, ${ }^{1} \mathrm{~K}$ Walters, ${ }^{1} \mathrm{M}$ Leverton, ${ }^{1} \mathrm{P}$ Rapaport, ${ }^{1} \mathrm{R}$ Herat-Gunaratne 2J Beresford-Dent, ${ }^{1} \mathrm{C}$ Cooper. ' University College London, UK; ${ }^{2}$ University of Bradford, UK

\subsection{6/bmjopen-2021-QHRN.28}

Background Dementia rarely travels alone. In the UK, almost 8 in every 10 people with dementia have another chronic condition. Due to the impact of dementia on important selfmanagement processes, partnership working across the care network at home and primary care is required to manage both cognitive and physical health. Trust is integral to this relationship to effectively involve people with dementia in their physical health care.

Objective To explore how the self-management of comorbid long-term conditions is experienced and negotiated by people with dementia and their carers.

Methods Secondary thematic analysis of 82 semi-structured interviews (11 people with dementia, 22 family carers, 19 health professionals and 30 homecare staff) from community settings across United Kingdom.

Results We identified three overarching themes: 1) The process of substituting self-management; 2) Communication in the care 